\title{
Process Standardization and Quality Evaluation of Yogurt Fortified With Noni Juice
}

\author{
H. W. Deshpande ${ }^{1}$, S. D. Katke ${ }^{1^{*}}$ and A. S. Kulkarni ${ }^{2}$ \\ ${ }^{1}$ Dept. of Food Microbiology \& Safety, College of Food Technology, \\ VNMKV, Parbhani, India \\ ${ }^{2}$ Dept. of Food Processing Technology, A D Patel Institute of Technology, New V.V. Nagar, \\ Anand, Gujarat, India \\ *Corresponding author
}

K e y w o r d s
Yogurt fortification,
Noni juice,
Lactobacillus
bulgaricus,
Streptococcus
thermophilus

\section{A B S T R A C T}

The present study was planned to investigate the possibility of noni juice incorporation in yogurt prepared with artificial sweeteners and to observe its effects on physico-chemical, sensorial and microbiological quality. Yogurt was prepared by standardized method with 3 per cent inoculum and fermented at $45^{\circ} \mathrm{C}$ temperature with different concentration of Noni juice (viz. 3, 6 and 9 per cent). The results revealed that increase in addition of Noni juice linearly increased the setting time, acidity and synergies of the product while $\mathrm{pH}$ and TSS decreased. Proximate analysis showed that moisture content increased with increasing concentration of noni juice while fat, protein, carbohydrates and ash contents were not significantly affected. It was concluded that yogurts prepared from cow milk with addition of 3 per cent noni juice found to be more acceptable than other treatments. Moreover, noni juice incorporated also resulted in better microbiological quality of yogurt.

\section{Introduction}

Yogurt is a cultured dairy product generally fermented with mixture of two species i.e. Lactobacillus bugaricus and Streptococcus thermophilus. It has soft, friable custard like consistency and a clean distinct acid flavour
(Kadam et al., 2010). Yogurt supplies high quality of protein and is excellent source of calcium, phosphorus and potassium (Meydani, 2006). In industrialized world, yogurt is generally prepared using cow's milk. Whole milk, partially skimmed milk, skim milk or whole milk enriched with 
cream may be used, to lower or raise the fat content as desired. The main processing steps involved in Yogurt manufacturing include standardization of milk (fat and protein content), homogenization, milk heat treatment, incubation, fermentation, cooling and storage. The purpose of the present study was to optimize inoculum (Streptococcus salivarius subsp. thermophillus and Lactobacillus delbrueckii spp. bulgaricus) level, setting temperature and sugar concentration in development of cow milk yogurt.

Noni (Morinda citrifolia), FamilyRubiaceae, originated in India and is now distributed in the continents of Asia, Australia, South America and Africa.

Polynesians identified the medicinal uses of noni fruits. Noni is also known as pain killer bush, head ache tree due to its excellent medicinal properties (Morton, 1992; Wang and Brett, 2002). It has been used as food and medicinal purposes for more than 2000 years ago (Wang and Brett, 2002; Mathivanan et al., 2005; Satwadhar et al., 2011). Noni fruit contains several phytochemicals, of which 160 compounds have already been identified. It also contains organic acids, several anthraquinones for e.g., damnacanthal, phenolic compounds and alkaloids. The fruit of $\mathrm{M}$. citrifolia contains high amount of calcium, potassium, phosphorus and magnesium. Due to its high nutritional content, the fruit is now used for the extraction of juice, which is used as health drink throughout the world (Wang and Su, 2001).

In the view of the promising health benefits of probiotic bacteria, artificial sweeteners, Noni fruit having high dietary fiber content, these natural functional ingredients are incorporated in cow milk to develop fruit fortified low calorie Yogurt which will be acceptable as therapeutic food product using fermentation technology.

\section{Materials and Methods}

Cow milk of Red Sindhi breed was obtained from local market. Chemicals used in this investigation were of analytical grade.

Pure culture of Streptococcus salivarius subsp. thermophillus and Lactobacillus delbrueckii spp. bulgaricus were obtained from National Chemical Laboratory, NCIM, Pune (MS) India.

The pure cultures were subcultured on slants prepared from MRS media in laminar flow (De Mann et al., 1960) and the culture which was obtained from sub culturing and inoculated in conical flask containing sterilized $50 \mathrm{ml}$ cow milk and the milk was incubated at $45^{\circ} \mathrm{C}$ till the firm coagulum was formed.

Batch culture was prepared by inoculating 3 per cent of mother culture into $100 \mathrm{ml}$ of sterilized cow milk and incubated at $45^{\circ} \mathrm{C}$ till firm coagulum was formed. The bulk culture was stored in refrigeration.

\section{Preparation of Noni Fortified Yogurt}

Experimental yogurt samples were prepared as per the method described by Patil et al., (2009) with the suitable modifications as follows:

\section{Standardization}

The process was begun with standardization of components of milk. A fat level was adjusted to 2.0-3.5 \% by separating cream with the help of centrifuge. The serum solids content of the milk were increased to 
10.5-11.5 \% by adding skim milk powder and casein at the rate of $4 \%$ and $0.3 \%$ respectively.

\section{Homogenization}

Homogenization was operated at about 200 $\mathrm{kg} / \mathrm{cm}^{2}$ pressure and temperature $55^{\circ} \mathrm{C}$ to retards fat separation.

\section{Addition of Sugar}

The sugar was added at the rate of 10 per cent.

\section{Heat Treatment}

The homogenized milk was heated to about $90-95^{\circ} \mathrm{C}$ for $10 \mathrm{~min}$ and cooled to $42^{\circ} \mathrm{C}$ to destroy the pathogenic organisms.

\section{Standardized formulation for Yogurt preparation}

\section{Inoculation}

The active starter culture was inoculated in 1:1 ratio of St. thermophillus and $L$. bulgaricus at the rate of $3 \%$ of total inoculation and mixed well with the help of a stirrer (Atta et al., 2009).

\section{Incubation}

The milk is incubated at different temperatures of $45^{\circ} \mathrm{C}$ for the period till the desired acidity is attained.

\section{Packaging and Storage}

Yogurts were packed in plastic cups, cooled and stored at about $5^{\circ} \mathrm{C}$. Various parameters of Yogurt preparation are summarized by Deshpande et al., 2014 and recipe is given as follows:

\begin{tabular}{|l|l|l|l|l|}
\hline Ingredients & $\begin{array}{l}\text { Contr } \\
\text { ol }\end{array}$ & N1 & N2 & N3 \\
\hline Cow Milk (ml) & 100 & 97 & 94 & 91 \\
\hline Noni Juice (ml) & 00 & 03 & 06 & 09 \\
\hline Inoculum (ml) & 03 & 03 & 03 & 03 \\
\hline Sweetener $(\mathrm{g})$ & 10 & 10 & 10 & 10 \\
\hline Incubation Temp $\left({ }^{\circ} \mathrm{C}\right)$ & 45 & 45 & 45 & 45 \\
\hline Time (hr) & 06 & 06 & 06 & 06 \\
\hline
\end{tabular}

\section{Analysis of Yogurt}

\section{Setting time of Yogurt}

The setting time of sample was recorded from the time of incubation to just coagulum formed and it was recorded in hours (h).

\section{Determination of synersis}

Synersis was measured by the method of Modler et al., (1983). A mass of $25 \mathrm{~g}$ of Yogurt was weighed onto a wire mesh screen placed over a funnel in a graduated cylinder.

Samples were placed in a refrigerator at $6^{\circ} \mathrm{C}$ immediately after weighing. Synersis $(\mathrm{ml} / 100 \mathrm{~g})$ was expressed as the volume of exudate collected after $2 \mathrm{hr}$ of refrigeration.

\section{Physico-chemical analysis}

Physico-chemical of yogurt such as total soluble solids (TSS), $\mathrm{pH}$ and acidity were determined as per standard (A.O.A.C., 1990).

\section{Sensory Evaluation}

15 semi-trained panel members having previous experience of sensorial evaluation of food products were selected for carrying out the sensory evaluation and asked for 
description sensory evaluation of yogurt for appearance, color, flavour, taste and texture as overall acceptability as followed by Kadam et al., (2010).

\section{Results and Discussion}

The present investigation was carried out for preparation and standardization of noni juice fortified yogurts. Further, it was studied for its physico- chemical properties, sensory characteristics.

The qualities of yogurt such as physical properties, chemical composition and sensory acceptability were determined.

\section{Physico-chemical properties of fruit juices}

The data pertaining to the physico-chemical properties of noni fruit juice is recorded and presented in Table 1.

The color characteristics of fruit juices were recorded by using tintometer readings of $\mathrm{R}+\mathrm{Y}+\mathrm{B}$. The results indicate that values recorded for noni juice $10.4 \mathrm{R}, 10.2 \mathrm{Y}$ and 3B. It was further observed that noni juice contain clear and sparkling solution.

TSS, pH and acidity of Noni juice was observed to be $8.60^{\circ} \mathrm{Bx}, 3.62$ and $1.25 \%$ respectively.

The results for noni juice and pineapple juice were in close agreement with the studies of Yanine et al., (2006).

Proximate composition of Milk and Noni Juice

The data pertinent to proximate composition of noni and pineapple juice is reported and presented in Table 2.The proximate analysis of noni and pineapple fruit juice revealed that there was significant difference in nutrient content of milk and noni juice.

The results for noni juice were in close agreement with the studies of Yanine ChanBlanco et al., (2006). The purpose of finding the nutritional composition was to study the effect of addition of Noni juice concentrations on physico-chemical as well as sensory qualities of product.

\section{Effect of addition of noni fruit juice on physicochemical properties of yogurt}

The physico-chemical properties of the Yogurt samples reflect the effectiveness of the process and suitability of selected ingredients.

The physico- chemical properties of noni juice fortified Yogurt samples prepared from the different proportions of ingredients are presented in Table 3.

The setting time of samples was found to be increased with an increase in concentration of fruit juice fortification. Similar findings for synersis of carrot juice fortified yogurts were cited by Salwa et al., (2004) in their scientific literature. Moreover, the lesser Synersis value indicates the better quality of prepared yogurts as it affects other physicochemical properties of product. It is found from the values that the total soluble solids content of juice fortified yogurt samples decreased with the increase in the concentration of added juice.

The acidity of fortified yogurt samples increased with the decrease in total solids content of samples. This may be attributed to the increase in the availability of moisture for activity of starter.

The values show that the $\mathrm{pH}$ of the fruit juice fortified Yogurt samples went on 
decreasing as the acidity of Yogurt samples increased. This may be due to increased rate of fermentation and the presence of lactic acid producing organisms.

In general, it could be observed that increase in addition of noni juice linearly increased the setting time, acidity and synersis of the product while the parameters like $\mathrm{pH}$ and TSS decreased with increasing concentration of noni juice.

\section{Effect of addition of noni fruit juice on proximate composition of yogurt}

The proximate compositions of noni juice fortified yogurts show their nutritional constituents which significantly affect its quality characteristics and are presented in Table 4.

Noni juice increased moisture content while TSS, protein, fat, carbohydrate and ash content decreased. The moisture content of fortified yogurt samples was found to be increased with increasing concentration of Noni juice, whereas total solids content was found to be decreased.

The fat, protein, carbohydrates and ash contents were not significantly affected; however all these parameters were found to be decreased. The accepted samples N1 contained moisture $85.27 \%$, total solids $14.23 \%$, protein $3.21 \%$, fat $3.76 \%$, carbohydrate $5.17 \%$ and ash $0.74 \%$ per cent respectively.

\section{Effect of addition of Noni fruit juice on sensory qualities of Yogurt}

The effect of addition of noni fruit juice on sensory qualities was studied and the mean score values of sensory qualities of noni fruit juice fortified Yogurts are presented Table 5.
The juice fortified yogurts were analyzed for their organoleptic acceptance by semitrained panel members with respect to the characteristics such as appearance, color, flavor, taste, texture and overall acceptability. All these organoleptic properties of Yogurts were decreased as juice concentration increased in noni juice fortified yogurt. Among all the fortified samples, the Yogurt with 3 per cent noni juice was found superior than other two fortified Yogurt samples. In case of Texture, lower concentration of juice does not affect the texture so much where as higher concentration adversely affected the texture. In case of taste, the samples with lower juice concentrations were acceptable than samples with higher juice concentrations.

This may be due to the bitterness causing chemical compounds which were present in Noni juices. The higher overall acceptability was found for the sample N1 to which 3 per cent noni juice was added after fermentation over the control.

\section{Microbial quality of Noni fortified Yogurts}

Yogurt prepared from different concentrations of artificial sweetener and noni fruit juice were evaluated for microbial quality as total plate count, total coliform count and yeast and mold count. The results obtained were recorded as colony forming unit per gram of sample i.e. cfu/g for total plate count and yeast and mold count and most probable number per gram i.e. MPN/g for total coliform count reported in Table 6 . The sample preparations for microbiological analysis were carried out by using serial dilution technique. Among all the samples prepared using different dilutions, the samples of the dilutions $10^{6}, 10^{3}$ and $10^{2}$ were selected for the measurement of total plate count, total coliform count and yeast and mold count respectively. 
Table.1 Physico-chemical properties of Noni fruit juice

\begin{tabular}{|l|l|}
\hline Physico-chemical Properties & Result \\
\hline Color & $10.4 R+10.2 Y+3 B$ \\
\hline T.S.S. (\%) & 8.60 \\
\hline pH & 3.62 \\
\hline Acidity (\%) & 1.25 \\
\hline
\end{tabular}

Table.2 Proximate composition of Noni fruit juice and Cow Milk

\begin{tabular}{|l|c|c|}
\hline Parameters & Noni Juice & Cow Milk \\
\hline Moisture (\%) & 95.93 & $\mathbf{8 5 . 9 4}$ \\
\hline Protein (\%) & 0.43 & $\mathbf{3 . 4 2}$ \\
\hline Fat (\%) & 00 & $\mathbf{4 . 4 6}$ \\
\hline Carbohydrates (\%) & 3.45 & $\mathbf{5 . 0 2}$ \\
\hline Ash (\%) & $\mathbf{0 . 2 3}$ & $\mathbf{0 . 7 1}$ \\
\hline
\end{tabular}

Table.3 Physico-chemical properties of yogurt fortified with noni fruit juice

\begin{tabular}{|l|c|c|c|c|}
\hline \multirow{2}{*}{ Parameters } & \multicolumn{4}{|c|}{ Samples } \\
\cline { 2 - 5 } & Control & N1 & N2 & N3 \\
\hline Setting Time (hr) & 6.0 & 6.17 & 6.25 & $\mathbf{6 . 4 1}$ \\
\hline Synersis (\%) & 3.0 & 3.6 & 4.2 & $\mathbf{4 . 7}$ \\
\hline T.S.S. (\%) & 22.50 & 22.20 & 21.85 & $\mathbf{2 1 . 6 0}$ \\
\hline pH & 4.47 & 4.43 & 4.37 & $\mathbf{4 . 3 2}$ \\
\hline Acidity (\%) & $\mathbf{0 . 8 1}$ & $\mathbf{0 . 8 3}$ & $\mathbf{0 . 8 7}$ & $\mathbf{0 . 9 2}$ \\
\hline
\end{tabular}

Table.4 Proximate composition of yogurt fortified with noni fruit juice after fermentation

\begin{tabular}{|l|c|c|c|c|}
\hline \multirow{2}{*}{ Parameters (\%) } & \multicolumn{4}{|c|}{ Samples } \\
\cline { 2 - 5 } & Control & N1 & N2 & N3 \\
\hline Moisture & 84.68 & 85.37 & 85.96 & $\mathbf{8 6 . 7 2}$ \\
\hline Total Solids & 15.02 & 14.23 & 13.57 & $\mathbf{1 1 . 8 9}$ \\
\hline Protein & 3.52 & 3.21 & 3.08 & $\mathbf{2 . 9 2}$ \\
\hline Fat & 3.85 & 3.76 & 3.62 & $\mathbf{3 . 5 7}$ \\
\hline Carbohydrates & 5.62 & 5.17 & 4.74 & $\mathbf{4 . 2 7}$ \\
\hline Ash & $\mathbf{0 . 7 7}$ & $\mathbf{0 . 7 4}$ & $\mathbf{0 . 7 1}$ & $\mathbf{0 . 6 8}$ \\
\hline
\end{tabular}


Table.5 Effect of addition of noni juice on organoleptic qualities of yogurt

\begin{tabular}{|l|l|l|l|l|l|l|}
\hline Samples & Appearance & Color & Flavor & Taste & Texture & $\begin{array}{l}\text { Overall } \\
\text { Acceptability }\end{array}$ \\
\hline Control & 8.8 & 8.6 & 8.5 & 8.7 & 8.8 & $\mathbf{8 . 8}$ \\
\hline N1 & 8.1 & 8.3 & 8.4 & 8.4 & 8.0 & $\mathbf{8 . 1}$ \\
\hline N2 & 7.9 & 7.3 & 7.5 & 7.8 & 7.2 & $\mathbf{7 . 5}$ \\
\hline N3 & 7.4 & 7.3 & 7.4 & 7.3 & 7.1 & $\mathbf{7 . 1}$ \\
\hline Mean & 8.06 & 7.88 & 7.85 & 8.05 & 7.78 & $\mathbf{7 . 9 0}$ \\
\hline S.E. & 2.54 & 2.59 & 2.65 & 2.79 & 2.32 & $\mathbf{2 . 5 2}$ \\
\hline C.D. at 5\% level & $\mathbf{7 . 0 2}$ & $\mathbf{7 . 1 9}$ & $\mathbf{7 . 3 5}$ & $\mathbf{7 . 7 4}$ & $\mathbf{6 . 4 4}$ & $\mathbf{6 . 9 8}$ \\
\hline
\end{tabular}

Table.6 Effect of noni juice fortification on microbial quality of yogurts

\begin{tabular}{|l|c|c|c|}
\hline Samples & $\begin{array}{c}\text { Total Plate Count } \\
\text { (cfu/g) }\end{array}$ & $\begin{array}{c}\text { Total Coliform Count } \\
\text { (MPN/g) }\end{array}$ & $\begin{array}{c}\text { Yeast and Mold Count } \\
\text { (cfu/g) }\end{array}$ \\
\hline Control & 64 & 27 & $\mathbf{4 5}$ \\
\hline N1 & 75 & 29 & $\mathbf{5 1}$ \\
\hline N2 & 82 & 25 & $\mathbf{4 7}$ \\
\hline N3 & $\mathbf{8 7}$ & $\mathbf{2 3}$ & $\mathbf{4 2}$ \\
\hline
\end{tabular}

Values illustrated in Table 6 indicated the growth of microorganisms in both control Yogurt and Yogurt with noni fruit juice. It is also observed that total plate count increased with an increase in fruit juice concentrations. It was in the range of 75 to $87 \mathrm{cfu} / \mathrm{g}$ in noni juice fortified Yogurts and 83 to $91 \mathrm{cfu} / \mathrm{g}$ in pineapple juice fortified Yogurts. The presented values indicated that coliform organisms were detected in control Yogurt. Coliform counts markedly decreased from 29 to $23 \mathrm{MPN} / \mathrm{g}$ in noni juice fortified Yogurts with an increase in added juice concentrations. There were significant differences in Coliform count between control yogurt (27 MPN/g) and yogurt with fruit juices.

In case of noni juice fortified Yogurt this may be due to the inhibitory effect of noni upon Coliform organisms. In addition, noni is considered as an antibacterial agent against pathogenic microorganisms (Wang and Brett, 2002) especially intestinal pathogens (Bushnell et al., 1950). These pathogens may get access into Yogurt either before or even after processing rendering the product unsafe for human consumption.

The illustrated values indicated that yeast and mold counts decreased with increased noni juice concentrations from 51 to 42 $\mathrm{cfu} / \mathrm{g}$ in respective fortified yogurts.

There was significant difference in yeast and mold count between plain and Yogurt with fruit juices. Noni exhibited significant antimicrobial and antifungal activity against various strains of bacteria and fungi (Gerson and Paul, 2002). Similar findings for fruit juice fortification were cited by Salwa et al., (2004) in scientific literature.

Thus in the light of the scientific data of the present investigation, it may be concluded that the Yogurts prepared from cow milk with addition of 3 per cent noni juice found to be more acceptable than other treatments. 
Moreover, Noni juice incorporated also resulted in better microbiological quality of Yogurt.

\section{References}

A.O.A.C., 1990. Official methods of analysis. Association of official analytical chemists. $15^{\text {th }}$ edition. Washington D.C.

Atta, M.S., Malik, M.H., Akhtar, Z. and Tariq, M. 2009. Influence of different amounts of starter cultures on the quality of Yogurt prepared from buffalo milk. Pak. J. Zool. Suppl. Ser., 9: 129-134.

Bushnell, O.A., Fukuda, M. and Makinodian, T. 1950. The antibacterial properties of some plants found in Hawaii. Pacific Sci, 4: 167-183.

DeMann, J.C., Rogosa, M. and Sharpe, M.E. 1960. A medium for the cultivation of Lactobacilli. J. Appl. Bact. 23: 130-135.

Deshpande H. W. Shaikh S.A., Syed Imran Hashmi and Deshpande R.H. 2015. Effect of varying inoculum levels, setting temperatures and sugar concentrations of quality of cow milk Yogurt. Green Farming. 6(2): Accepted.

Gerson, S. and Paul, A.K. 2002. Formulation for inhibiting fungal and microbial growth comparing $M$. citrofolia puree juice. United States Patent, 7048952. Kadam, P.S., Kale, R.V. and Syed, I.H. 2010. Effect of different varieties of date palm paste incorporation on quality characteristics of Yogurt. Res. J. Dairy Sci. 4(2): 12-17.

Mathivanan, N., Surendiran, G., Srinivasan, K., Sagadevan, E. and Malarvizhi, K. 2005. Review on the current scenario of Noni research: Taxonomy, distribution, chemistry, and medicinal and therapeutic values of Morinda citrifolia L., Int. J. Noni Res., 1: 1- 9.

Meydani, S.N. 2006. Is frozen Yogurt as nutritive as regular Yogurt? 'A review'. USDA. Human Nutrition Research Center, England.

Modler, H.W., Larmond, M.E., Lin, C.S., Froehlich, D. and Emmons, B. 1983. Physical and sensory properties of yogurt stabilized with milk proteins, $J$. Dairy Sci., 6: 422-429.

Morton, J.F. (1992). The ocean-going noni, or Indian mulberry (Morinda citrifolia, Rubiaceae) and some of its colorful relatives. Econ. Bot., 46(3): 241-56.

Patil, A.P., Chavan, K.D. and Bhosale, D.N. 2009. Influence of addition of guava pulp and sugar on sensory quality of guava Yogurt. J. Dairying, Foods and Home Sci. 28(2): 95-100.

Salwa, A., Aly, E.A., Galal, A. and Neimat, A. E. 2004. Carrot Yogurt: sensory, chemical, microbiological properties and consumer acceptance. Pak. J. Nutr. 3(6): 322-330.

Satwadhar, P. N., Deshpande, H. W., Syed, I.H., and Syed, K.A. 2011. Nutritional composition and identification of some of the bioactive components in Morinda citrifolia juice. Int. J. Pharmacy and Pharm. Sci. 3(1): 58-59.

Wang, M.Y. and Brett, J.W. 2002. Morinda citrofolia (noni). A literature review and recent advances in noni research. Acta pharmacol. Sin. 23(12): 1127-1141.

Yanine, C.B., Fabrice, V. A. and Max M.P. 2006. The noni fruit (Morinda citrifolia L.): A review of agricultural research, nutritional and therapeutic properties. $J$. Food Compo. Anal. 19(6-7): 645-654.

\section{How to cite this article:}

Deshpande, H. W., S. D. Katke and Kulkarni, A. S. 2019. Process Standardization and Quality Evaluation of Yogurt Fortified With Noni Juice. Int.J.Curr.Microbiol.App.Sci. 8(10): 179-186. doi: https://doi.org/10.20546/ijcmas.2019.810.018 